\title{
Genel Cerrahi Tarafından Opere Edilerek Yoğun Bakım Ünitesine Kabul Edilen Geriatrik Hastaların İncelenmesi
}

\section{Evaluation of Geriatric Patients who were Operated By General Surgery and Admitted to Intensive Care Unit}

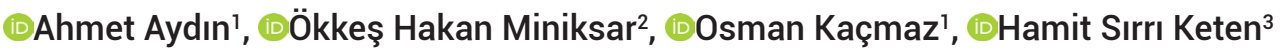 \\ 'Turgut Özal Üniversitesi, Malatya Eğitim ve Araştırma Hastanesi, Anesteziyoloji ve Reanimasyon Bölümü, Malatya, Türkiye \\ ${ }^{2}$ Yozgat Bozok Üniversitesi Tıp Fakültesi, Anesteziyoloji ve Reanimasyon Anabilim Dalı, Yozgat, Türkiye \\ ${ }^{3}$ Gaziantep Üniversitesi, Tıp Fakültesi, Aile Hekimliği Anabilim Dalı, Gaziantep, Türkiye
}

Copyright@Author(s) - Available online at www.dergipark.org.tr/tr/pub/medr

Content of this journal is licensed under a Creative Commons Attribution-NonCommercial 4.0 International License.

\begin{abstract}
Öz
Amaç: Bu çalışmada genel cerrahi tarafından ameliyat edilen ve postoperatif yoğun bakım ünitesine kabul edilen 65 yaş üzeri geriatrik hastaların geriye dönük olarak incelenmesi amaçlanmıştır.

Materyal ve Metot: Çalışmaya 2017-2018 yılları arasında hastanemiz genel cerrahi kliniği tarafından acil veya elektif olarak operasyona alınan ve postoperatif yoğun bakım ünitesine kabul edilen 54 geriatrik hasta dahil edildi. Hastaların demografık verileri, yoğun bakıma yatış endikasyonu, acil veya elektif cerrahi olup olmadığı, ameliyata alınma nedeni, Amerikan Anestezistler Derneği skoru, inotropik ajan ihtiyacı ve prognozları değerlendirildi.

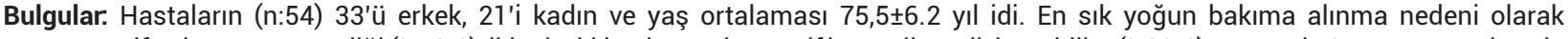
postoperatif solunum yetmezliği (\%42.6), ikinci sıklıkta ise perioperatif hemodinamik instabilite (\%29.6) saptandı. 65-74 yaş grubunda olgu sayısı daha fazla idi. En sık ileus (\%20.4) nedeniyle cerrahi yapıldığı tespit edildi. Hastaların yoğun bakım ünitesine kabulde entübasyon durumu ile Amerikan Anestezistler Derneği skoru arasındaki ilişkinin anlamlı olduğu belirlendi ( $p=0.017)$. Ortalama yatış süresi 3,6 $\pm 3,9$ gün olarak bulundu. 10 hasta (\%18.5) exitus oldu.

Sonuç: Geriatrik hastalarda postoperatif solunum sıkıntısı gelişme sıklığında artışın daha ön planda olduğu, kardiyak ve geçirdikleri cerrahi komplikasyonlara bağlı olarak da yoğun bakımda hemodinamik monitörizasyon ihtiyacının arttığı görülmüştür. Yaşlı hastalardaki cerrahi müdahalenin hasta klinik özelliklerine ve yapılan cerrahiye bağlı olarak postoperatif yoğun bakım ihtiyacını doğurabileceği mutlaka göz önünde bulundurulmalıdır.
\end{abstract}

Anahtar Kelimeler. Geriatrik hastalar; geriatrik cerrahi; yoğun bakım; mortalite

\begin{abstract}
Aim: In this study, we aimed to retrospectively examine geriatric patients over 65 years of age who were operated by general surgery and admitted to the postoperative intensive care unit.

Material and Method: A total of 54 geriatric patients who were urgently or electively operated by the general surgery clinic of our hospital and admitted to the postoperative intensive care unit between 2017 and 2018 were included in the study. The demographic data of the patients, the indication for ICU admission, whether there was an emergency or elective surgery, the reason for the surgery, the American Society of Anesthesiologists score, the need for inotropic agents and prognosis were evaluated.

Results: Of the patients ( $\mathrm{n}: 54), 33$ were men, 21 were women, and the mean age was $75.5 \pm 6.2$ years. The most common reason for admission to intensive care unit was postoperative respiratory failure (42.6\%) and the second most common reason was perioperative hemodynamic instability (29.6\%). The number of cases was higher in the 65-74 age group. It was found that surgery was performed mostly due to ileus (20.4\%). It was determined that the relationship between the intubation status of the patients in the intensive care unit and the American Society of Anesthesiologists score was significant $(p=0.017)$. The mean length of intensive care hospitalization was $3.6 \pm 3.9$ days. 10 patients $(18.5 \%)$ died.

Conclusion: It was observed that the increase in the frequency of postoperative respiratory distress in geriatric patients was more prominent, and the need for hemodynamic monitoring in the intensive care unit increased due to cardiac and surgical complications they had. It should be kept in mind that surgical intervention in elderly patients may cause the need for postoperative intensive care depending on the patient's clinical characteristics and the surgery performed.
\end{abstract}

Keywords: Geriatric patients; geriatric surgery; intensive care unit; mortality 


\section{GíRiş}

Dünyada 2019 yılı için 72,6 yıl olan insan yaşam süresinin hızlı bir şekilde uzayarak, 2050 yılında 77,1 yıla yükseleceği öngörülmektedir. Dünya nüfusu hızla yaşlanmakta olup, yaş grupları içerisinde en hızlı büyüyen grubun, 65 yaş ve üzeri bireylerden oluşan grup olduğu belirlenmiştir (1). Adrese dayalı nüfus kayıt sistemine göre Türkiye'de 2018 yılı için nüfusun \%8,8'ini 65 yaş ve üzeri kişiler oluşturmaktadır (2). Bu durum nüfus içerisindeki payı her geçen gün artan, 65 yaş ve üzeri bireylere sunulan sağlık hizmetlerinin büyük öneme sahip olduğunu ve öneminin çok daha fazla artacağını ortaya koymaktadır.

Amerika Birleşik Devletleri'nde yoğun bakım ünitesine (YBÜ) hasta kabullerinin yaklaşık \%42-52'sini 65 yaş ve üzeri hastaların oluşturduğu saptanmıştır $(3,4)$. Yapılan bir çalışmada yoğun bakım ünitelerinde takip edilen yaşlı hasta oranının \%53,6 olduğu ifade edilmiştir (4). Amerika Birleşik Devletleri'nde 2030 yılına kadar 60 yaş ve üzeri bireylerin $\% 21$ 'inin cerrahi operasyon geçireceği ve yılda 7 milyondan fazla 65 yaş üzeri bireye günübirlik cerrahi uygulanacağı öngörülmektedir (5). Geriatrik nüfusun artması ile yaşlı hastaların acil servise başvurularında artış meydana gelmiştir. Cerrahi yöntemler ve teknikler ile postoperatif bakımdaki gelişmelere bağlı olarak geriatrik nüfusa cerrahi girişim yapılma sıklığı artmıştır $(6,7)$. Yaşlanma ile kronik hastalıkların ve fonksiyonel bozuklukların görülme sıklığı artmaktadır. Kardiyak, solunum sistemi, endokrin, serebral ve renal hastalıkların geriatrik hastalara eşlik etmesi beraberinde bu hastalarda perioperatif ve postoperatif dönemde morbidite ve mortalitede artışa neden olmaktadır (8). Mekanik ventilatör (MV) ihtiyacı ve hemodinamik instabilitenin bu hasta gruplarında artışı ile yoğun bakım desteğine daha fazla ihtiyaç söz konusu olmaktadır. Ayrıca bu hasta grubunda yoğun bakım mortalitesi gençlere göre daha yüksektir (5-8).

$\mathrm{Bu}$ çalışmanın amacı, genel cerrahi bölümü tarafından opere edilen ve postoperatif YBÜ'ye kabul edilen 65 yaş ve üzeri hastaların klinik özelliklerini ve YBÜ süreçlerini tanımlamaktır.

\section{MATERYAL VE METOT}

Çalışma için 23536505-604.02 sayılı izin alındıktan sonra, Ocak 2017-Aralık 2018 tarihleri arasında hastanemiz genel cerrahi bölümü tarafından acil veya elektif olarak cerrahi yapılan, postoperatif YBÜ'ye kabul edilen ve 24 saat üzeri yatan hastaların (>65 yaş) verileri retrospektif olarak incelenerek gerçekleştirildi. Hastane otomasyon sistemi ve hasta dosyasında eksik bilgileri olan hastalar çalışmaya dahil edilmedi. Verileri tam olan 54 hasta çalışmaya dahil edildi. Çalışmaya alınan hastaların demografık verileri, YBÜ yatış endikasyonu, acil veya elektif cerrahi olup olmadığı, cerrahinin gerçekleşme nedeni, YBÜ'de yatış süresi, Amerikan Anestezistler Derneği (ASA) skoru, mekanik ventilatör ihtiyacı, intraoperatif inotrop ajan ihtiyacı, YBÜ'den çııış durumu incelendi. Birden fazla YBÜ'ye kabulü olan hastaların postoperatif sadece ilk yatışları değerlendirmeye alındı.

\section{İstatistiksel Analiz}

İstatistiksel değerlendirmede versiyon SPSS 21.0 paket programı kullanıldı. Çalışma verileri değerlendirilirken sayısal veriler için tanımlayıcı istatistikler (frekans, ortalama \pm standart sapma) kullanıldı. Veriler sayı, (\%) olarak verildi. İki kategorik değişken arasındaki ilişki değerlendirilirken ise ki kare testi kullanıldı. İstatistiksel anlamlılık düzeyi için $\mathrm{p}$ $<0.05$ kabul edildi.

\section{BULGULAR}

$\mathrm{Bu}$ çalışmada belirtilen tarihler arasında, dahil edilme kriterlerini taşıyan ve YBÜ'ye kabul edilen 54 hastanın dosyası retrospektif olarak incelendi. Hastaların 33'ü $(\% 61,1)$ erkek, 21 'i $(\% 38,9)$ kadın ve yaş ortalaması $75,5 \pm 6,2$ yıl olarak tespit edildi. Hastaların 27 'si $(\% 50,0) 65-74,20$ 'si $(\% 37,0) 75-84$ yaş, 7 'si $(\% 13,0)>85$ yaş aralığında saptandı.

Hastaların 23'ü $(\% 42,6)$ postoperatif solunum yetmezliği, 16 'sı $(\% 29,6)$ perioperatif hemodinamik instabilite ve 8 'i $(\% 14,8)$ hemorajik şok sebebiyle yoğun bakım ünitesine kabul edildi. Solunum yetmezliği tüm yaş gruplarında en sık YBÜ kabul sebebi olarak yer almaktaydı. Hastaların yoğun bakım ünitesine alınma endikasyonları Tablo 1 'de sunuldu. Yoğun bakım kabulündeki şuur durumu en yüksek oranda $\% 33,3$ (n:18) bilinç durumu açık, en az oranda \%5 (n:5) ise bilinç durumu kapalı olarak değerlendirildi.

Hastaların cerrahi endikasyonları incelendiğinde; en sık ileus $(n=11, \% 20,4)$, mide kanseri $(n=7, \% 13,0)$ ve inkarsere herni $(n=7, \% 13,0)$ olduğu belirlendi (Tablo 2). Hastaların 34 'ü $(\% 63,0)$ acil, 20 'sinin $(\% 37,0)$ ise elektif olarak cerrahiye alındığı saptandı.

Hastaların 20'sinin (\%37) ASA 1-2, 34'ünün (\%63) ASA 3-4 risk skoruna sahip olduğu belirlendi. Hastaların 19'u $(\% 35,2)$ MV'ye bağlı entübe, 35'i $(\% 64,8)$ ekstübe edilmiş durumda idi. Entübe olarak YBÜ'ye kabul edilen hastaların en fazla ASA 3-4 ve 65-74 yaş grubunda olduğu tespit edildi. Ayrıca hastaların entübe olma durumu ile ASA skoru arasındaki ilişkinin anlamlı olduğu belirlendi $(p=0.017)$ (Tablo 3).

Ortalama YBÜ yatış süresi $3,6 \pm 3,9(\min =1, \max =21)$ gün olarak saptandı. Hastaların 28'i (\%51,9) 24-48 saat arası, 11 'i $(\% 20,4)$ 48-72 saat arası, 15'i $(\% 27,8) 72$ saat ve üzerinde YBÜ'de yatış süresine sahipti (Tablo 4). Peroperatif hemodinamik instabilite gelişip pozitif inotrop ajana ihtiyaç duyan $13(\% 24,1)$ hasta tespit edilirken, $41(\% 75,9)$ hastada herhangi bir inotrop ajan ihtiyacının olmadığı saptandı.

Hastalarda tek kronik hastalığı olan hasta sayısı 18 kişi $(\% 33,3)$, iki veya daha fazla kronik hastalığa sahip hasta sayısı 36 kişi $(\% 66,7)$ olarak tespit edildi. Mortalite oranları; tek kronik hastalığa sahip olanlar ile $(n=1, \% 5,6)$, birden fazla kronik hastalığa sahip olanlar $(n=9, \% 25)$ arasında benzer özellik göstermekteydi $(p=0,138)$. Ayrıca hastalara eşlik eden başlıca kronik hastalıklar; Hipertansiyon (HT) $(n=28)$, koroner arter hastalığı $(n=19)$, kronik obstruktif akciğer hastalığı $(n=12)$, diabetes mellitus $(n=9)$, kalp yetmezliği $(n=7)$, astım $(n=5)$ ve kronik böbrek yetmezliği $(n=3)$ olarak saptandı.

Yoğun bakım takip ve tedavisi yapılan 54 hastadan 10'u 
$(\% 18,5)$ exitus olurken, 44'ünün ise $(\% 81,5)$ servise nakli yapıldığı saptandı (Tablo 5). Exitus olan 10 hastadan 6'sının hemorajik şok nedeniyle YBÜ'ye kabul edildiği belirlendi.
Peroperatif hemodinamik instabilite nedeniyle kabul edilen hastalarda ise (\%29,6, E/K: 11/5 kişi) mortalitenin görülmediği tespit edildi.

\section{Tablo 1. Hastaların yoğun bakım ünitesine kabul nedenleri}

\section{Yatış nedenleri}

Postoperatif solunum yetmezliği, n (\%)

Hemorajik şok, n (\%)

Akut miyokard infarktüsü, n (\%)

Metabolik problemler, n (\%)

Perioperatif hemodinamik instabilite, n (\%)

Perioperatif kardiyak arrest, n (\%)

Diğer, $\mathbf{n}(\%)$

Toplam, n (\%)

Diğer: Sepsis, Akut böbrek yetmezliği

$\begin{array}{llll}65-74 \text { yaş } & 75-84 \text { yaş } & >85 \text { yaş } & \text { Toplam } \\ 10(18,5) & 9(16,7) & 4(7,4) & 23(42,6) \\ 5(9,3) & 2(3,7) & 1(1,9) & 8(14,8) \\ 1(1,9) & 0(0,0) & 0(0,0) & 1(1,9) \\ 1(1,9) & 2(3,7) & 0(0,0) & 3(5,6) \\ 9(16,7) & 5(9,3) & 2(3,7) & 16(29,6) \\ 0(0,0) & 1(1,9) & 0(0,0) & 1(1,9) \\ 1(1,9) & 1(1,9) & 0(0,0) & 2(3,7) \\ 27(50) & 20(37) & 7(13) & 54(100)\end{array}$

Tablo 2. Hastaların cerrahi endikasyonları

\section{Cerrahi endikasyonları}

Akut kolesistit, kolelitiazis

Akut apandisit

İnkarsere herni

Mide kanseri

Rektum kanseri

Kolon kanseri

İleus

Diğer

Over kanseri

Meme kanseri

Toplam n

6

4

7

7

5

3

11

9

1

1

54
$\%$

11,1

7,4

13,0

13,0

9,3

5,6

20,4

16,7

1,9

1,9

100
E/K

$3 / 3$

$0 / 4$

$6 / 1$

$6 / 1$

4/1

$0 / 3$

$7 / 4$

$7 / 2$

$0 / 1$

$0 / 1$ 


\section{Yaş grupları}

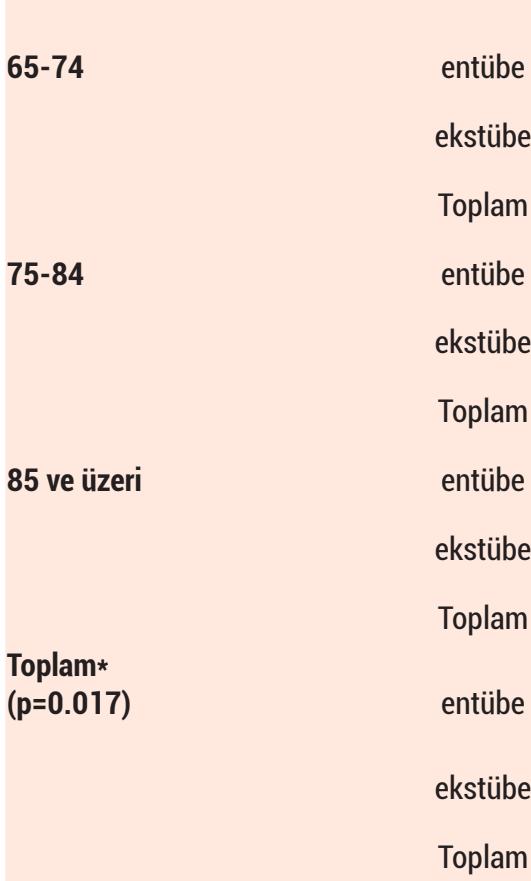

\section{ASA 1-2}

(n)

(n)

(n)

(n)

(n)

(n)

(n)

(n)

(n)

(n) (\%)

(n) $(\%)$

(n)

(\%)

2
9
11

3

20

37
ASA

ASA 3-4

Toplam

9

11

16

27

4

16

20

4

3

7

6

$19(35,2)$

16

$35(64,8)$
18

34

67

\section{4}

100,0

* $p<0,05$. Ki-kare test.

Tablo 4. Olguların yoğun bakım ünitesinde yatı̧ süreleri

Ortalama yatış süresi $3,6 \pm 3,9$ gün

\section{Gruplar}

24-48 saat arası kalanlar

65-74

75-84

$>85$

Toplam

16

8

4

28

29,6

5

48-72 saat arası kalanlar

9,3

14,8

7,4

51,9

4

11

7,4

2

20,4

6

72 saat ve üzeri kalanlar

n 6

8

15

11,1

27

14,8

27,8

Toplam

$\begin{array}{ll}\mathrm{n} & 27\end{array}$

20

54

50

37

13

100

\section{Tablo 5. Hastaların ek hastalıkları ile mortalite arasındaki dağlımı}

Tek yandaş hastalı̆ı olan hastalar, $\mathrm{n}(\%)$
Birden fazla yandaş hastalığı olan hastalar, $\mathrm{n}(\%)$

*Toplam, n (\%)

*p:0,138. $\mathrm{p}>0.05$. Fisher's Exact Test

\section{Exitus}

$1(5,6)$

$9(25)$

$10(18,5)$

\section{Servis}

$17(94,4)$

$27(75)$

$44(81,5)$

7

3,7

19

(1)

13

3100




\section{TARTIŞMA}

Bu çalışmada postoperatif YBÜ'ye kabul edilen geriatrik hastaların klinik özellikleri ve yoğun bakım süreçleri incelendi. Geriatrik hastalarda postoperatif solunum yetmezliği, geçirilen cerrahiye bağlı olarak gelişen komplikasyonlar nedeniyle de hemodinamik instabilite gelişmekte ve sonucunda yoğun bakım takibine ihtiyaç duyulmaktadır.

Geriatrik hastalarda yapılan başarılı cerrahi müdahaleler beraberinde anestezistlerin karşılaştıkları geriatrik hastaların sayısının artmasına neden olmuştur. Yaşlanma ile organ rezervlerinde ve fonksiyonel kapasitede azalma olurken, anabolik süreçlerde gerileme ve patolojik olayların sıklığında artma meydana gelmektedir. Yaş, ASA skoru, spesifik cerrahi faktörler, intraoperatif tedavi ve komorbid durumlar cerrahi morbidite ve mortaliteye etki etmektedir (9-11).

Bu çalışmada yoğun bakım ünitesinde takip edilen hastaların \%61,1'inin erkek ve en sık görülen yaş aralığının 65-74 olduğu saptandı. Yapılan çalışmalarda YBÜ'de cerrahi operasyon sonrası takip ve tedavisi yapılan geriatrik hastaların en sık 65-74 yaş aralığında ve erkek cinsiyetine sahip olduğu tespit edilmiştir $(12,13)$. Çalışma literatür ile benzerlik göstermektedir. Geriatrik yaş grubunda populasyonların en önemli nüfusunu 6574 yaş grubunun oluşturması, bu yaş grubunun sağlık hizmetinden faydalanma ve sağlık hizmet ihtiyacına paralel olarak yoğun bakım ünitelerinde geriatrik hastalar arasında daha çok sayıda bulunmasına sebep olmaktadır.

2040 yılına kadar nüfusun \%24'ünün 65 yaş ve üzerinde olacağı ve bunların yarısına cerrahi müdahale yapılacağı öngörülmektedir (14). Cerrahi operasyonların artması yaşlı olan ve anesteziklere hemodinamik olarak daha duyarlı olan bu hastalarda postoperatif komplikasyonların sıklığında artışa yol açabilecektir. Bu hemodinamik instabilite sonucunda yoğun bakım ihtiyacının artacağı açıkça gözükmektedir. Bu çalışmada hastaların yoğun bakım ünitesine kabulündeki en sık neden solunum yetmezliği $(\% 42,6)$ daha sonra ise hemodinamik instabilite olduğu $(\% 29,6)$ saptandı. Solunum yetmezliğine bağlı olarak ileri yaşam desteği ihtiyacı özellikle yoğun bakım ünitelerinde yük oluşturacaktır. Çağımızda COViD-19 pandemisine bağlı olarak yoğun bakım üniteleri büyük öneme sahip olup bu departmanların yükünü arttıracak işlemlerden mümkün olduğunca uzak durmak gerekmektedir.

Hastaların geçirdikleri cerrahi operasyonlar içerisinde en sık olarak; ileus $(\% 20,4)$, inkarsere inguinal herni (\%13) ve safra kesesi ve yolları $(\% 11,1)$ kaynaklı operasyonlar olduğu belirlendi. Ayrıca olguların \%63'ünün acil, $\% 37$ 'sinin ise elektif şartlarda cerrahi operasyona alındığı tespit edildi. Mayir ve arkadaşlarının çalışmasında gözlenen cerrahi müdahaleler; safra kesesi ve yolları $(\% 22,6)$, herni $(\% 18,9)$ ve kolon-rektum $(\% 17,5)$ cerrahisi şeklinde tespit edilmiştir (13). Aynı çalışmada geriatrik olgulara (297) yapılan operasyonların 196'sının elektif şartlarda,
101 'inin acil şartlarda uygulandığı ifade edilmiştir (15). Çalışmamız Mayir ve arkadaşların çalışmasıyla cerrahi endikasyonları açısından benzer özellik göstermektedir. Çalışmamızda acil şartlarda operasyon oranı ise Mayir ve arkadaşlarının çalışmasına göre yüksek oranda olduğu gözükmektedir. Bu durum çalışmamızın sadece genel cerrahi departmanında opere edilen vakaları kapsaması, diğer çalışmanın ise tüm cerrahi departmanları kapsayan vakalardan oluşmasından kaynaklanabilir. Geriatrik yaş grubunda yer alan bireylerin acil olarak ameliyata alınma oranının yüksek olması önemli bir bulgudur. Sağlık hizmet sunumunda yer alan çalışanların bu kritik bakım hastalarını yakın olarak takip etmesi acil ameliyat ve mortalite oranının düşmesine katkı sağlayacaktır.

Hastaların tamamının en az bir kronik hastalığa sahip olduğu ve bunlar içerisinde en sık; HT \%51,8 ve koroner arter hastalığı \%35,1 görüldüğü tespit edildi. Yaşlanma süreci ile kronik hastalıkların görülme sıklığında artış ve fiziksel kapasitede bir azalma meydana gelmektedir. Literatürde 65 yaşın üzerindeki nüfus içerisinde \%90'ının bir, \%35'inin iki, \%23'ünün üç, \%15'ininde dört ve daha fazla kronik sağlık sorununa sahip olduğu bildirilmektedir (16). Geriatrik grup üzerine yapılmış farklı tipteki birçok çalışmada bu hastalıklardan en fazla oranda HT (\%25$66,8)$ ve koroner arter hastalığı $(\% 15,4-46,2)$ bildirilmiştir (17-22). Çalışmamız literatür ile uyum göstermekle birlikte HT'nin en sık görülen kronik hastalık olması önemli bir bulgudur. Geriatrik yaş grubunda HT risk faktörlerinden korunmaya yönelik koruyucu halk sağlığı politikaları uygulanmalı ve bu gruba eğitim verilmelidir. Böylelikle önemli bir sağlık sorunu ve sosyal sorun (ekonomik, iş gücü kaybı) olan HT prevalansı azalacaktır.

Olguların operasyon öncesi ASA risk skorlamasında \%37'sinin ASA 1-2, \%63'ünün ASA 3-4 olduğu ve bu olgular içerisinde postoperatif yoğun bakıma kabullerinde entübe olarak alınan hasta grubunun ASA 3-4 risk grubunda daha fazla sayıda $(\% 29,6)$ olduğu tespit edildi. Ayrıca bu gruptaki olgular içerisinde daha fazla sayıda acil endikasyon nedeniyle cerrahi müdahale gerçekleştiği bulunmuştur. Yaş, kronik hastalıklar ve operasyon nedeni bu durumda belirleyici etmenler olduğu düşünülmektedir. Taş ve arkadaşlarının cerrahi operasyon sonrası yoğun bakım servisinde takip edilen hastalarda yaptığı çalışmada ASA 1 (\%3.9), ASA 2 (\%71.7), ASA 3 (\%22.1), ASA 4 (\%2.2) olarak saptanmıştır (13). Bu durum çalışmamızda yer alan hastaların acil şartlarda cerrahi operasyona alınma oranının, elektif şartlarda alınma oranına göre daha fazla oranda olması ve hastaların daha ağır klinik öyküye sahip olmasından dolayı kaynaklanmış olabilir.

Hastaların yoğun bakımdaki ortalama yatış süresi 3,6 gün olarak tespit edildi. Yapılan benzer çalışmalarda bu süre 1.98-3.41 gün olarak belirtilmiştir (23-24). Çalışmamız yapılan benzer çalışmalarla uyum göstermekte olup, hastaların klinik ve cerrahi operasyon sebepleri bu sürelerde değişikliğe sebep olabilecek parametrelerdir.

Bu çalışmada inotropik ajan ihtiyacı vakaların \%24,1'inde 
gerçekleşti. Benzer bir çalışmada inotropik ajan ihtiyacı vakaların \%26,3'ünde tespit edilmiştir (24). İnotropik ajan ihtiyacına yaş, kronik hastalık tanısı ve yapılan cerrahi operasyona bağlı olarak postoperatif ihtiyaç duyulmakta veya intraoperatif başlanmış tedavi devam ettirilmektedir. Çalışmamız literatür ile benzerlik göstermektedir.

Yaşlı hastalarda cerrahi girişim yüksek morbidite ve mortalite riski taşımaktadır. 75 yaş üstü hastalarda yoğun bakım mortalitesi, altta yatan hastalık ve kabuldeki hastalığın ciddiyetine göre \%22 ile \%31 arasında değiştiği bildirilmiştir. 65 yaş üzeri hastalarda ise mortalite oranı bir çalışmada \%14,7, başka bir çalışmada ise $\% 24$ oranında bulunmuştur $(7,22,25,26)$. Çalışmamızda olguların mortalite oranı \%18,5 olarak saptandı. Vakaların mortalitesine sosyodemografik ve klinik özellikleri etki etmektedir. Çalışmamız literatür ile uyum göstermektedir.

\section{SONUÇ}

Cerrahi operasyon sonrasında yoğun bakım ünitelerinde takip ve tedavi ihtiyacı geriatrik hastalarda önemli bir durumdur. Özellikle vakaların solunum yetmezliği ve geçirdikleri cerrahi komplikasyonlara bağlı olarak hemodinamik instabilite nedeniyle yoğun bakımda monitörize bakıma ihtiyacının arttığı görüldü. Bu yaş grubunda kronik hastalığın vakaların tamamında görülmesi önemli olup buna yönelik koruyucu sağlık politikaları geliştirilmelidir. Bu hastaların yakın takibi geriatrik hastalarda acil cerrahi endikasyon oranını düşürecek, mortalite ve morbidite üzerine olumlu katkı sağlayacaktır.

Finansal destek: Çalışmayı maddi olarak destekleyen kişi/kuruluş yoktur.

Çıkar Çatışması: Yazarlar arasında herhangi bir çıkar çatışması yoktur.

Etik onay: Çalışma Helsinki Deklarasyonunda belirtilen ilkelere uyularak yapıldı. Malatya Klinik Araştırmalar Etik Kurulu tarafindan onaylandı.

\section{REFERENCES}

1. World Population Prospects 2019: Highlights. Https://population.un.org/wpp/Publications/Files/ WPP2019_10KeyFindings.pdf. (Erişim Tarihi:18.11.2020)

2. TÜiK nüfus projeksiyonları 2018-2080. https://www. tuseb.gov.tr/enstitu/tacese/haber_detay.php?id=72. (ErişimTarihi:18.11.2020)

3. Marik PE. Management of the critically ill geriatric patient. Crit Care Med 2006; 34:76-82.

4. Ülger Z, Cankurtaran M. Yoğun bakımda yaşlı hasta. Yoğun Bakım Dergisi 2006;6:94-100.

5. Çilingir D, Bayraktar N. Günübirlik cerrahi süreci ve hemşirelik bakımı. Hacettepe Üniversitesi Hemşirelik Yüksekokulu Dergisi 2006;13:69-81.

6. Çilingiroğlu N, Demirel S. Yaşlılık ve yaşlı ayrımcılığı. Türk Geriatri Dergisi 2004; 7: 225-30.

7. Blansfield JA, Clark SC, Hofmann MT, et al. Alimentary tract surgery in the nonagenarian: Elective vs. emergent operations. J Gast Surg 2004;8:539-42.

8. Ersoy A, Ervatan Z, Ali A, et al. Kalça Cerrahisinde Anestezi Deneyimlerimiz. Ok Meydanı Tıp Dergisi 2013;29:33-6.

9. Hepağuşlar H, Geriatrik Anestezi. İç: Keçik Y, editör. Temel Anestezi. Güneş Tıp Kitapevleri; 2012.s. 489-501.

10. Miller R.D. Miller Anestezi 6.Basım. İzmir Güven Kitabevi 2010:2435-49.

11. Cook DJ, Rooke GA. Priorities in Perioperative Geriatrics. Anesthesia \& Analgesia 2003;96:1823-36.

12. Kaya Z, Arıcı S, Süren M, et al. Geriatrik Hastaların Bir Yıllık Retrospektif Değerlendirilmesi. Gaziosmanpaşa Üniversitesi Tıp Fakültesi Dergisi 2012;4:29-36.

13. Tas N, Mutlu T, Yağan Ö, et al. Altmış beş yaş üstü geriatrik vakalarımızın peroperatif değerlendirmesi ve postoperatif erken dönem sonuçları; retrospektif analiz. Gaziosmanpaşa Üniversitesi Tıp Fakültesi Dergisi 2015;7:89-99.

14. Asouhidou I, Asteri T, Sountoulides P, et al. Early postoperative mortality in the elderly: A pilot study. BMC Research Notes 2009;2:118.

15. Mayir B, Altınel Ö, Özerhan İH, et al. Yaşlı hastalarda cerrahi sonrası mortaliteye etki eden faktörler. Anatol J Clin Investig 2010:4:32-5.

16. Zülfıkaroğlu B, Özalp N, Keşkek M, et al. 80 yaş ve üzerindeki hastalarda acil abdominal cerrahi. Turk J Geriatr 2005;8:1159.

17. Loğoğlu A, Ayrık $C$, Köse $A$, et al. Acil servise başvuran travma dışı geriatrik olguların demografik özelliklerinin incelenmesi. Tr J Emerg Med 2013;13:171-9.

18. Çelik S, Kavacık D, Nair A, et al. Cerrahi Girişim Geçiren Yaşlı Hastalarda Bilişsel Fonksiyon Bozukluğunun Değerlendirilmesi. Bakırköy Tıp Dergisi 2015;11:66-73.

19. Erden İA, Akıncı SB, Pamuk AG, et al. Yoğun bakımda yatan geriatrik hastaların retrospektif olarak değerlendirilmesi. Turkish J Geriatrics 2009; 12:171-6.

20. Çakmak ME. Göğüs hastalıkları servisimizde izlenen 85 yaş ve üzeri geriatrik hastaların değerlendirilmesi. İzmir Göğüs Hastanesi Dergisi 2016:30:167-72.

21. Özdemir L, Kocoğlu G, Sumer $H$, et al. Sivas il merkezinde yaşlı nüfusta bazı kronik hastalıkların prevalansı ve risk faktörleri. Cumhuriyet Üniversitesi Tıp Fakültesi Dergisi 2005;27:89-94.

22. Karaveli A, Cerit GN, Özyurt E. Evaluation of admission causes and mortality rates of 65 years of age and older patients admitted from the emergency department to the intensive care unit. Turkish J Geriatrics. 2018;21:515-21.

23. Kanar $M$, Armağan $R$, Oç $Y$, et al. Geriatrik kalça kırıklı hastalar için yoğun bakım ünitesi gerekli mi? Ş.E.E.A.H. Tıp Bülteni 2017;51:201-6.

24. Daşar U. Postoperatif yoğun bakım ünitesinde takip edilen 80 yaş üstü kalça kırıklı hastaların bir yıllık retrospektif değerlendirilmesi. Turkish J Geriatrics 2018;21:81-6.

25. Bozkurt D, Kılavuz A, Caferov N, et al. Non-traditional mortality predictors for geriatric intensive care unit patients Turkish J Geriatrics 2018;21:323-32.

26. Hamel MB, Davis RB, Teno JM, et al. Older Age, Aggressiveness of Care and Survival for Seriously ill, Hospitalized Adults. Ann Intern Med 1999;131:721-8. 